\title{
Community health-promotion interventions with physical activity: does this approach prevent obesity?
}

\author{
Mikael Fogelholm and Marjaana Lahti-Koski
}

'The UKK Institute for Health Promotion Research, Tampere; ${ }^{2}$ National Public Health Institute, Helsinki, Finland

\begin{abstract}
Background: Prevention of weight gain is a primary strategy in tackling the obesity epidemic.

Objective: This review summarizes results of community interventions for prevention of cardiovascular diseases, with dietary changes and increased physical activity as target behaviours, and change in obesity as one outcome variable.

Design: A Medline search was used to identify studies. The focus behaviour was physical activity, but all of the five selected interventions also had dietary changes as an essential component.

Results: The interventions were aimed at prevention of cardiovascular diseases, and all had dietary changes, increased physical activity and decreased prevalence of obesity as means to achieve the main objective. The duration of intervention was 4-7 years. Out of the four projects with physical activity assessments, two did not observe any significant intervention effects on physical activity. The residents of the intervention communities of the Minnesota Heart Health Study were somewhat more physically active at the end of the follow-up. In the Stanford Five-City Project, the intervention had a positive effect on physical activity in independent, cross-sectional samples. Most projects did not find any intervention impact on body mass index (BMI). In the Stanford Five-City Project, BMI increased less in treatment than in control communities, but this effect was observed only by using the cross-sectional, independent surveys. Conclusion: It seems that the increase in energy expenditure due to physical activity was not large enough. To enable improvements, future interventions may need a stronger emphasis on changes in the local physical and social environment.
\end{abstract}

Keywords: Cardiovascular diseases, eating, environment, exercise, overweight.

Received 28 October 2002; Accepted: 31 October 2002

\section{Introduction}

Prevention of weight gain is generally regarded as a primary strategy to tackle the obesity epidemic (1). Based on both cross-sectional and observational, prospective evidence, many studies have underscored the important role of physical activity in prevention of weight gain (2). Unfortunately, there have been no large community interventions to test the hypothesis regarding promotion of a prudent diet and daily physical activity, versus change in weight. However, the behavioural approaches used in trials for prevention of cardiovascular diseases have many common elements with prevention of obesity.

This brief review summarizes the results of large community interventions for prevention of cardiovascular diseases, with dietary changes and increased physical activity as target behaviours, and change in obesity as one outcome variable. Because of the increased interest in physical activity as a means of preventing weight gain (2), the focus of this review is on physical activity, but all selected studies also had dietary changes as an essential component.

\section{Presentation of studies}

The studies were identified by a Medline search with the following search strategy:

(community(Text Word) AND (physical activity(Text Word) OR exercise(Text Word))

AND (obesity(Text Word) OR weight(Text Word))

AND (intervention(All Fields) OR trial(All Fields))

AND English(Language)) AND human(MeSH Terms)). 
In addition, the reference lists of two comprehensive reviews were used $(3,4)$. Only studies published in 1990 or later were included in the present review. Although the definition of "community" may include a focus on common social and cultural elements (5), a community is defined here as a geographically bounded area (a city or another large residential area). "Community intervention" means an intervention with an objective to achieve and evaluate widespread changes in an entire community, rather than in individuals (6). The accepted papers had to have a clearly defined physical activity component as a part of the intervention, and change in body weight, body mass index (BMI) or prevalence of obesity as an outcome variable.

Only five interventions fulfilled the criteria (Table 1) (7-16). The interventions were aimed at decreasing the mortality and morbidity of cardiovascular diseases, but all had dietary changes, increased physical activity and decreased prevalence of obesity as means to achieve the main objective. Three projects were designed to include both intervention and control communities $(9,10,14)$. The Bootheel Heart Health Project had the state as a comparison area (7), whereas the CINDI project (Countrywide Integrated Non-Communicable Diseases Intervention) was totally uncontrolled (8). The duration was similar in all interventions (4-7 years). The subjects were obtained by random cross-sectional sampling at the beginning and at the end of the follow-up $(7,9)$, or by a combination of cohort and independent cross-sectional surveys $(10,14)$. A convenience sample with active programme participants as subjects was used in the CINDI project (8).

The CINDI project (8) was mainly based on education received from general practitioners. Hence, the programme was closely integrated into primary medical care. All other projects based their intervention on more widespread educational approaches, that is, face-to-face counselling by health professionals and peers, and the use of mass media (television, radio, newspapers, printed materials). Moreover, the use of social support (organized groups, such as walking clubs), physical activity contests, opinion leaders and models, and risk factor screening were common to these interventions. Changes in the physical environment (e.g. the building of walking and fitness paths) were reported in one project only (7), whereas policy changes, with special labelling of foods in grocery stores and restaurants, were described in two interventions $(9,11)$.

\section{Main outcomes}

Out of the four projects with physical activity assessments, two $(7,9)$ did not observe any significant intervention effects on physical activity, although there was a tendency towards increased physical activity in the intervention areas of the Bootheel Heart Health project (7). The residents of the intervention communities of the Minnesota Heart Health Study were somewhat more physically active (self-reported) at the end of the followup (11). The increased physical activity was apparently due to an increase in activities with low intensity. In a separate substudy, a special exercise programme was launched at schools in intervention and control communities (11). Girls in the intervention communities reported significantly greater amounts of exercise than girls in control communities. Boys showed a similar tendency, but the difference between the intervention and control communities was smaller. In the Stanford FiveCity Project, the intervention had a positive effect on physical activity in the independent, cross-sectional samples, but not in the cohort survey (14, 16). The observed increase was seemingly due to an increased amount of usual daily activities, rather than to vigorous exercise (16).

Although the results on physical activity were positive in most projects, the intervention effects on body weight change were disappointing. Three projects did not find any intervention impact on $\operatorname{BMI}(7,9,13)$. Moreover, no change in the prevalence of overweight $\left(\mathrm{BMI}>25 \mathrm{~kg} \mathrm{~m}^{-2}\right.$ ) was seen in the uncontrolled CINDI project (8). In the Stanford Five-City Project, BMI increased less in treatment than in control communities, but this effect was observed only by using the cross-sectional, independent surveys (15).

\section{Discussion}

Decreased physical activity, rather than increased energy intake, seems to be associated with the recent increase in the prevalence of obesity $(17,18)$. Therefore, the hypothesis that increased physical activity prevents or at least decreases weight gain is apparently plausible. This hypothesis is strengthened by the fact that a majority of cross-sectional and observational studies have shown that high physical activity is associated with smaller weight gain (2). Unfortunately, the studies cited in this brief review show that the positive effects of physical activity in prevention of weight gain are not easily demonstrated in (controlled) interventions. 
Table I. Summary of the community interventions cited in this review

\begin{tabular}{|c|c|c|c|c|}
\hline Study and references & Design & Intervention methods & Changes in physical activity & Changes in obesity \\
\hline $\begin{array}{l}\text { Bootheel Heart Health Project, } \\
\text { USA (7) }\end{array}$ & $\begin{array}{l}\text { Intervention in six rural } \\
\text { counties in Missouri, USA. } \\
\text { The state as a comparison } \\
\text { area. Two cross-sectional } \\
\text { samples, } 5 \text { y interval }\end{array}$ & $\begin{array}{l}\text { Education, supervision, risk } \\
\text { factor screening, } \\
\text { environmental changes } \\
\text { (walking and fitness path) }\end{array}$ & $\begin{array}{l}\text { Percentage inactive in Bootheel } \\
\text { was reduced by } 1 \% \text {, and } \\
\text { increased in the state by } 3.7 \% \\
\text { (ns) }\end{array}$ & $\begin{array}{l}\text { Prevalence of overweight } \\
\text { increased. No intervention } \\
\text { effect, except in intervention } \\
\text { communities with active } \\
\text { coalitions }\end{array}$ \\
\hline CINDI project, Germany (8) & $\begin{array}{l}\text { Uncontrolled intervention } \\
\text { in one small provincial } \\
\text { town in Germany. Annual, } \\
\text { non-randomized, } \\
\text { cross-sectional samples, } \\
\text { for } 4 \text { y }\end{array}$ & $\begin{array}{l}\text { An educational programme } \\
\text { integrated into primary } \\
\text { medical care }\end{array}$ & Not assessed & $\begin{array}{l}\text { No change in prevalence of } \\
\mathrm{BMI}_{>} 25 \mathrm{~kg} \mathrm{~m}^{-2}\end{array}$ \\
\hline $\begin{array}{l}\text { Heartbeat Wales programme, } \\
\text { UK (9) }\end{array}$ & $\begin{array}{l}\text { Intervention in Wales, } \\
\text { matched control area in } \\
\text { north-east England. Two } \\
\text { cross-sectional samples, } 5 \\
\text { y interval }\end{array}$ & $\begin{array}{l}\text { Educational programmes, } \\
\text { environmental, organizational } \\
\text { and policy changes }\end{array}$ & $\begin{array}{l}\text { Percentage active subjects } \\
\text { increased in both areas by } \\
2-3 \% \text { units (ns) }\end{array}$ & $\begin{array}{l}\text { Percentage of overweight } \\
\text { residents increased in both } \\
\text { areas by } \mathrm{I}-2 \% \text { units (ns) }\end{array}$ \\
\hline $\begin{array}{l}\text { Minnesota Heart Health } \\
\text { Programme, USA (10-13) }\end{array}$ & $\begin{array}{l}\text { Three intervention and } \\
\text { three control cities. } \\
\text { Cohort and } \\
\text { cross-sectional surveys, } \\
\text { duration 6-7 y }\end{array}$ & $\begin{array}{l}\text { Educational, engagement of } \\
\text { opinion leaders and models, } \\
\text { supervision, risk factor } \\
\text { screening, policy changes, } \\
\text { special programmes to } \\
\text { increase physical activity }\end{array}$ & $\begin{array}{l}\text { Physical activity programmes } \\
\text { had a transient, positive effect } \\
\text { on activity levels. School } \\
\text { activity programmes had also a } \\
\text { positive effect on exercise } \\
\text { levels }\end{array}$ & $\begin{array}{l}\text { No long-term intervention } \\
\text { effects on BMI }\end{array}$ \\
\hline $\begin{array}{l}\text { Stanford Five-City Project, USA } \\
\qquad(14-16)\end{array}$ & $\begin{array}{l}\text { Two treatment and two } \\
\text { control cities. Four } \\
\text { cross-sectional surveys, } \\
\text { four repeated cohort } \\
\text { surveys, duration 5-6 y }\end{array}$ & $\begin{array}{l}\text { Educational programmes, lay } \\
\text { leaders, social support, } \\
\text { competitions. More focus on } \\
\text { physical activity at the end of } \\
\text { the intervention }\end{array}$ & $\begin{array}{l}\text { Intervention increased physical } \\
\text { activity ( } 7 \text { day energy } \\
\text { expenditure) in cross-sectional } \\
\text { assessments, but not in the } \\
\text { cohort assessment }\end{array}$ & $\begin{array}{l}\text { BMI increased less in } \\
\text { intervention cities } \\
\text { (cross-sectional assessment), but } \\
\text { no effect was seen in the } \\
\text { cohort assessment }\end{array}$ \\
\hline
\end{tabular}

BMI: body mass index; ns: not significant.

These failures to show clear intervention effects could be due to methodological problems. Difficulties in evaluating complex multifaceted interventions have been reported (9), and methods of assessing physical activity in large groups are quite crude and imprecise (19). Moreover, favourable secular trends in dietary choices as well as in smoking cessation could not only dilute intervention effects but also confound the effect of physical activity in prevention of weight gain.

In addition to these methodological issues, an obvious reason for the above discrepancy is that physical activity and energy expenditure in the intervention communities did not increase enough to counterbalance secular changes in food intake and daily activity (18). In the most successful intervention (the Stanford Five-City Project) the difference between estimated daily energy expenditure in intervention and control communities was $250 \mathrm{~kJ}$ day $^{-1}\left(60 \mathrm{kcal} \mathrm{day}^{-1}\right)$, which corresponds to a weekly difference of $1750 \mathrm{~kJ}$ (420 kcal) (15). This is close to the minimum amount of increased energy expenditure $\left(2090 \mathrm{~kJ}\right.$ week ${ }^{-1}$ or $\left.500 \mathrm{kcal}^{\text {week }}{ }^{-1}\right)$ that has been associated with improved maintenance of weight loss (2). However, it is probable that other studies were less successful in increasing total energy expenditure. There are several potential explanations for the problems in increasing physical activity in intervention communities.

The focus has been too much on traditional physical activity, rather than usual daily activities (lifestyle activity). The same problem is also seen in controlled obesity treatment trials. It is likely that large population segments may more readily accept increased lifestyle activity than more structured exercise training. Although one may presume that adherence to lifestyle activity might also be easier than to a more fixed exercise regimen, two con- 
trolled trials $(20,21)$ found adherence to these two approaches to be equal. Recent studies on the effects of lifestyle activity $(20,22)$ or multiple short-bout exercise (23) on weight change in overweight persons are encouraging. However, more research is needed to increase our understanding of how to increase unstructured, daily physical activity in people who live in a physical and social environment that does not reinforce regular, spontaneous activity.

There was too little priority for physical activity in the interventions. All interventions listed in Table 1 had a decrease in cardiovascular disease mortality and morbidity as a primary objective. This meant that the approaches were very comprehensive and physical activity served as just one focus of the intervention plan. Thus, a community intervention focusing only on obesity (13) and with physical activity as a focal point (6) may yield better results.

The interventions were too general and hence important subgroups were lost. For instance, Jeffery et al. (13) noted that the intervention effects were more clearly seen in residents with elevated serum cholesterol concentration or a history of obesity-related disease. Other potential subgroup targets for physical activity interventions could be people of lower socioeconomic status, minority groups and older adults (6).

A high-profile health-promotion programme extended even to the control area $(9,12)$. The intervention and control communities are not isolated: both areas are targets of health promotion through mass media and from physicians and other health professionals. The educational environment may already be saturated with health-promotion material, and therefore any additional efforts have only marginal effects (13).

All interventions had a strong emphasis on education, that is, their basic assumption was that increasing the level of knowledge about obesity-related risks, dietary choices and exercise behaviour will enable people to improve weight maintenance (13). It is notable that only the Bootheel Heart Health Project reported deliberate efforts to change the physical environment by the construction of walking and fitness paths (9). There are clearly several unused possibilities for modifying environments to facilitate or promote physical activity (6). These include increasing the safety and convenience of exercise facilities for all segments of the community, and improving the safety and availability of cycling and walking paths, as well as building stairways in public buildings and in workplaces. Some environmental changes are cheap and easy. Recently, Andersen et al. (24) showed how a simple and inexpensive sign at the bottom of a staircase in a shopping centre increased the proportion of people who used the stairs instead of an escalator from $5-6 \%$ to $6-8 \%$. New interventions should try to identify and modify several settings where a significant proportion of community members is present on a daily basis $(6,14)$.

This review has shown the apparent inability of past community interventions, with physical activity as one component, to prevent weight gain. This critical view does not mean, however, that community interventions are proven to be unsuccessful. Future interventions should be based on some of the cornerstones of previous interventions (e.g. individual guidance, social support by group counselling, mass media efforts tailored to the overall programme, and use of opinion leaders and peer leaders) but, in addition, a much stronger emphasis on changes in the local physical and social environment is needed. Moreover, the intervention should receive support from at least some national legislative and regulatory policies. However, the authors believe that the community rather than the national level should be the primary level of action. There is simply a need to find out how to do things better than in the past.

\section{References}

1. International Obesity Task Force (IOTF). Obesity. Preventing and managing the global epidemic. WHO/NUT/ NCB/98.1. Geneva: World Health Organization; 1998.

2. Fogelholm M, Kukkonen-Harjula K. Does physical activity prevent weight gain? A systematic review. Obes Rev 2000;1:95-111.

3. Glenny A-M, O'Meara S, Melville A, et al. The treatment and prevention of obesity, a systematic review of the literature. Int J Obes Relat Metab Disord 1997;21:71537.

4. Baranowski T, Anderson C, Carmack C. Mediating variable frameworks in physical activity interventions. How are we doing? How might we do better? Am J Prev Med 1998;15:266-97.

5. Paronen O, Oja P. How to understand a community community assessment for the promotion of health-related physical activity. Patient Educ Couns 1998;33:S258.

6. King AC. How to promote physical activity in a community, research experiences from the US highlighting different community approaches. Patient Educ Couns 1998;33:S3-S12.

7. Brownson RC, Smith CA, Pratt M, et al. Preventing cardiovascular disease through community-based risk 
reduction, the Bootheel Heart Health Project. Am J Public Health 1996;86:206-13.

8. Wiesemann A, Metz J, Nuessel E, et al. Four years of practice-based and exercise-supported behavioural medicine in one community of the German CINDI area. Countrywide Integrated Non-Communicable Diseases Intervention. Int J Sports Med 1997;8:308-15.

9. Tudor-Smith C, Nutbeam D, Moore L, Catford J. Effects of the Heartbeat Wales programme over five years on behavioural risks for cardiovascular disease, quasi-experimental comparison of results from $\mathrm{W}$ ales and a matched reference area. Br Med J 1998;316:818-22.

10. Murray DM, Kurth C, Mullis R, Jeffery RW. Cholesterol reduction through low-intensity interventions, results from the Minnesota Heart Health Program. Prev Med 1990;19:181-9.

11. Kelder SH, Perry CL, Klepp K-I. Community wide youth exercise promotion, long-term outcomes of the Minnesota Heart Health Program and the Class of Study. J Sch Health ; 63 1989;1993:21 8-23.

12. Luepker R V, Murray DM, Jacobs DR Jr, et al. Community education for cardiovascular disease prevention, risk factor changes in the Minnesota Heart Health Program. Am J Public Health 1994;84:1383-93.

13. Jeffery RW, Gray CW, French SA, et al. Evaluation of weight reduction in a community intervention for cardiovascular disease risk, changes in body mass index in the Minnesota Heart Health Program. Int J Obes Relat Metab Disord 1995;19:30-9.

14. Fortmann SP, Winkleby MA, Flora JA, et al. Effect of long-term community health education on blood pressure and hypertension control. The Stanford Five-City Project. Am J Epidemiol 1990;132:629-46.

15. Taylor CB, Fortmann SP, Flora J, et al. Effect of long term community health education on body mass index, the Stanford Five City Project. Am J Epidemiol 1991;134:235-49.

16. Young DR, Haskell WL, Taylor CB, Fortmann SP. Effects of community health education on physical activity knowledge, attitudes, and behavior. Am J Epidemiol 1996;144:264-74.

17. Prentice AM, Jebb SA. Obesity in Britain: gluttony or sloth? Br Med J 1995;311:437-9.

18. Fogelholm M, Männistö S, Pietinen $\mathrm{P}$, Vartiainen E. Determinants of energy balance and overweight in Finland 1982 and 1992. Int J Obes Relat Metab Disord 1996;20:1097-104.

19. Wareham NJ, Rennie KL. The assessment of physical activity in individuals and populations: why try to be more precise about how physical activity is addressed? Int J Obes Relat Metab Disord 1998; 22 (2 Suppl): S30-8.

20. Andersen RE, Wadden TA, Bartlett SJ, et al. Effects of lifestyle activity vs structured aerobic exercise in obese women. JAMA 1999;281:335-40.

21. Robinson TN. Reducing children's television viewing to prevent obesity. JAMA 1999;282:1561-7.

22. Dunn AL, Marcus BH, Kampert JB, et al. Comparison of lifestyle and structured interventions to increase physical activity and cardiorespiratory fitness. JAMA 1999;281:327-34.

23. Jakicic JM, Winters C, Lang W, Wing RR. Effects of intermittent exercise and use of home exercise equipment on adherence, weight loss, and fitness in overweight women. JAMA 1999;282:1554-60.

24. Andersen RE, Franckowiak SC, Snyder J, et al. Can inexpensive signs encourage the use of stairs? Results from a community intervention. Ann Intern Med 1998;129:363-9.

Dr Mikael Fogelholm
The UKK Institute for Health Promotion Research
PO Box 30
Fl-3350I Tampere
Finland
E-mail: mikael.fogelholm@ita.fi

